\title{
Notes on the vocalizations of Banded Prinia (Prinia bairdii)
}

Peter Boesman

In the following we briefly analyze and compare voice of the different races of Banded Prinia (Prinia bairdii). We also try to quantify the extent of any vocal differences using the criteria proposed by Tobias et al. (2010), as a support for taxonomic review. We have made use of sound recordings available on-line from Xeno Canto (XC) and Macaulay Library (ML).

Song of all races is a single (sometimes composite) note repeated at rather fast pace. Comparison of song of the different races:

\section{bairdii}

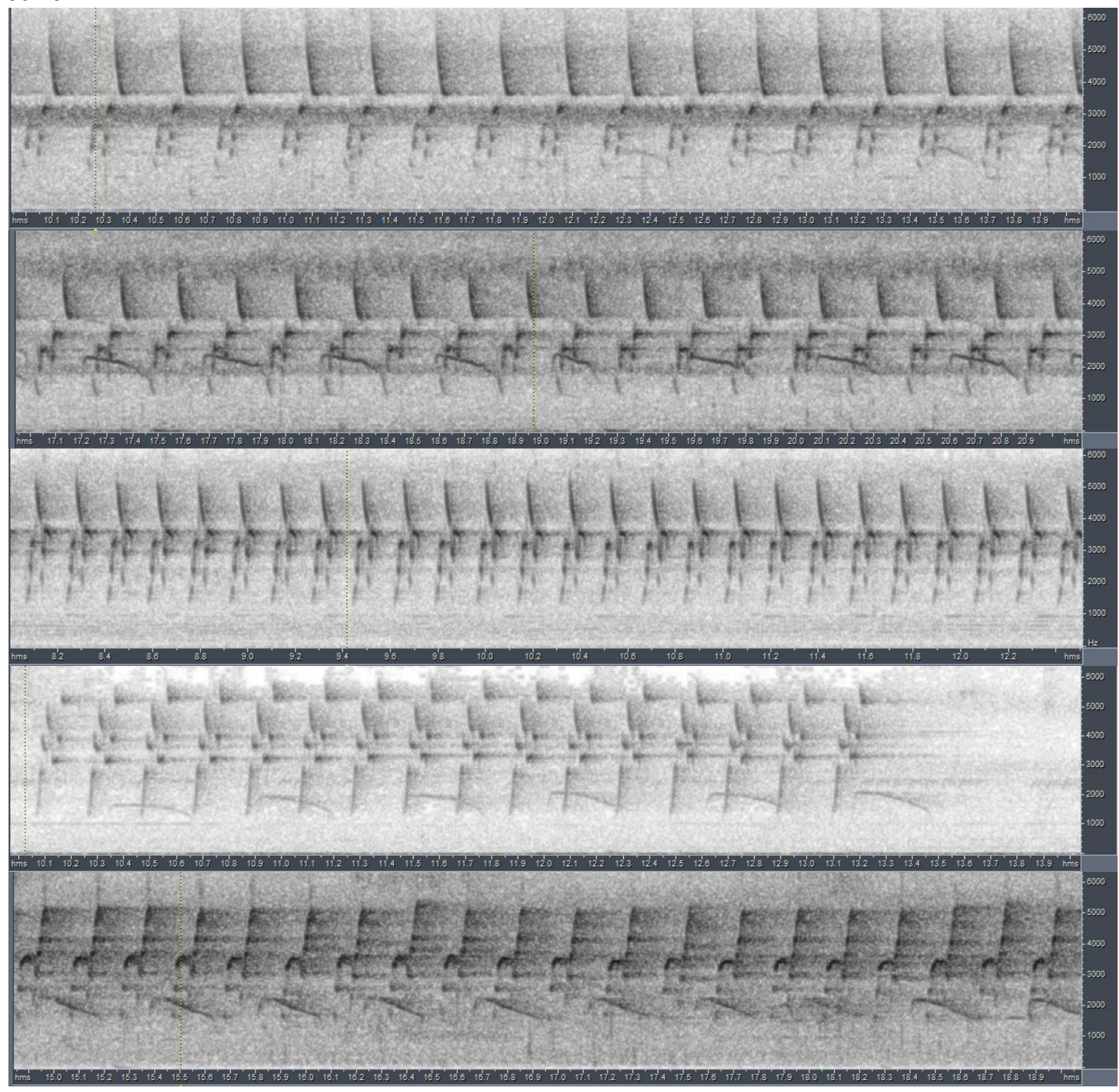




\section{HANDBOOK OF THE \\ BIRD S PF, THE WORLD \\ Aluve}

\section{ORNITHOLOGICAL NOTES}

obscura

Ruwenzori 2000m, eastern DR Congo

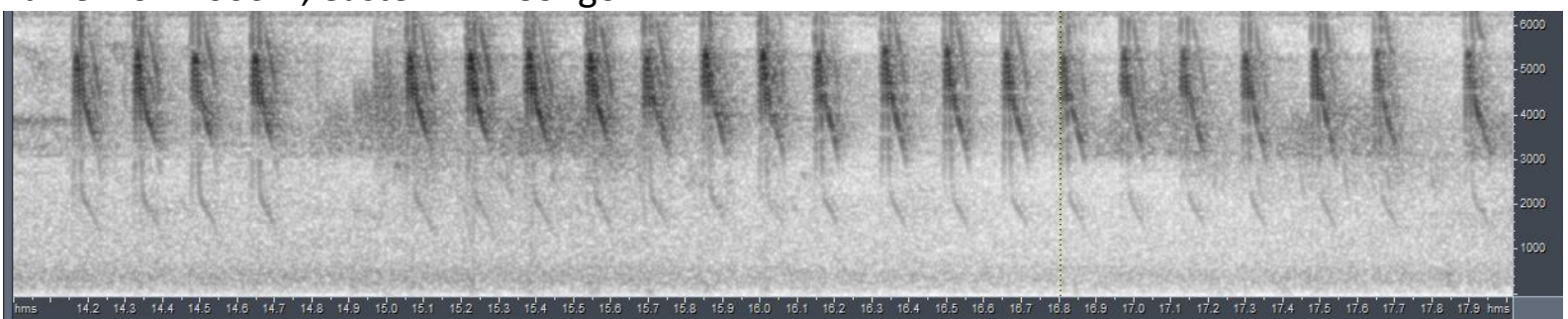

Lolwa 900m, eastern DR Congo

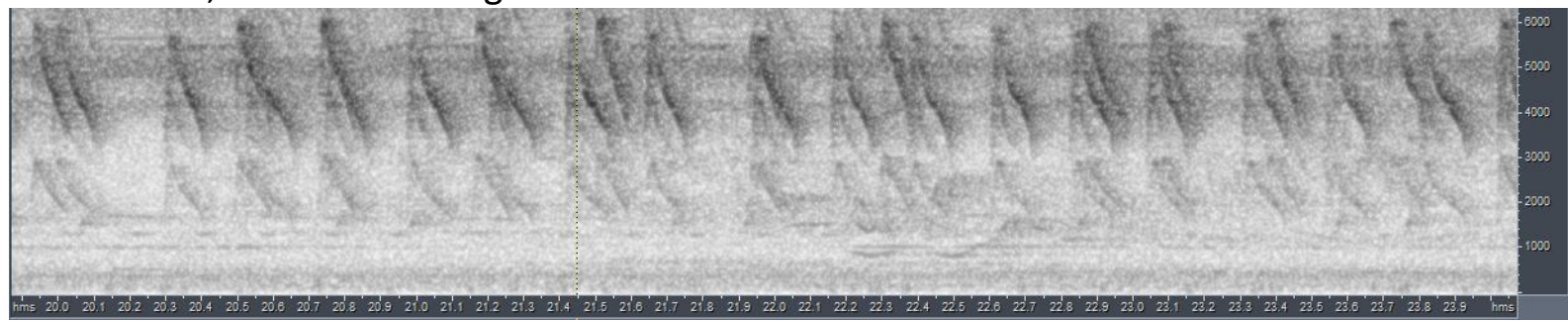

melanops

Kenya

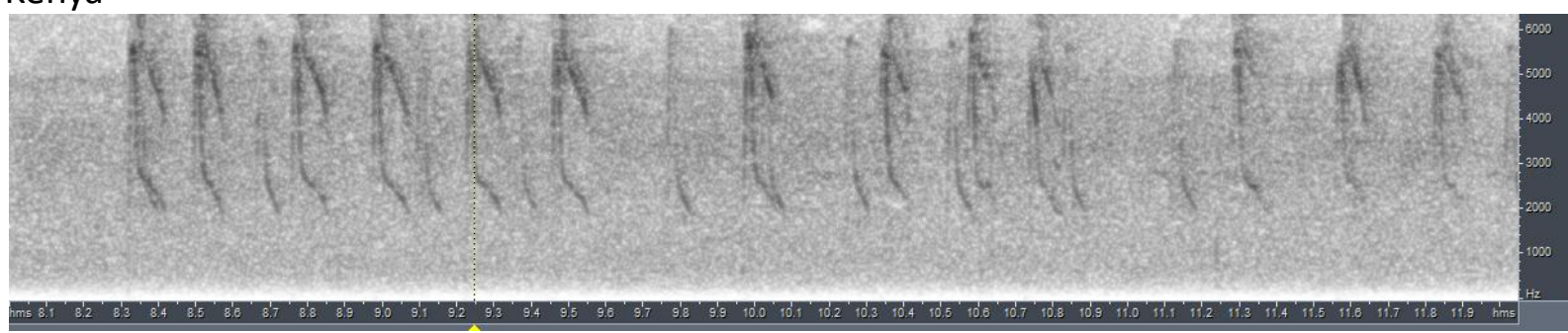

From the above, there seems to be quite an important difference between the repeated multi-element note (bairdii) and the simple dagger-shaped note (obscura/melanops).

Four additional recordings from Uganda require attention:

SW Uganda (impenetrable forest)

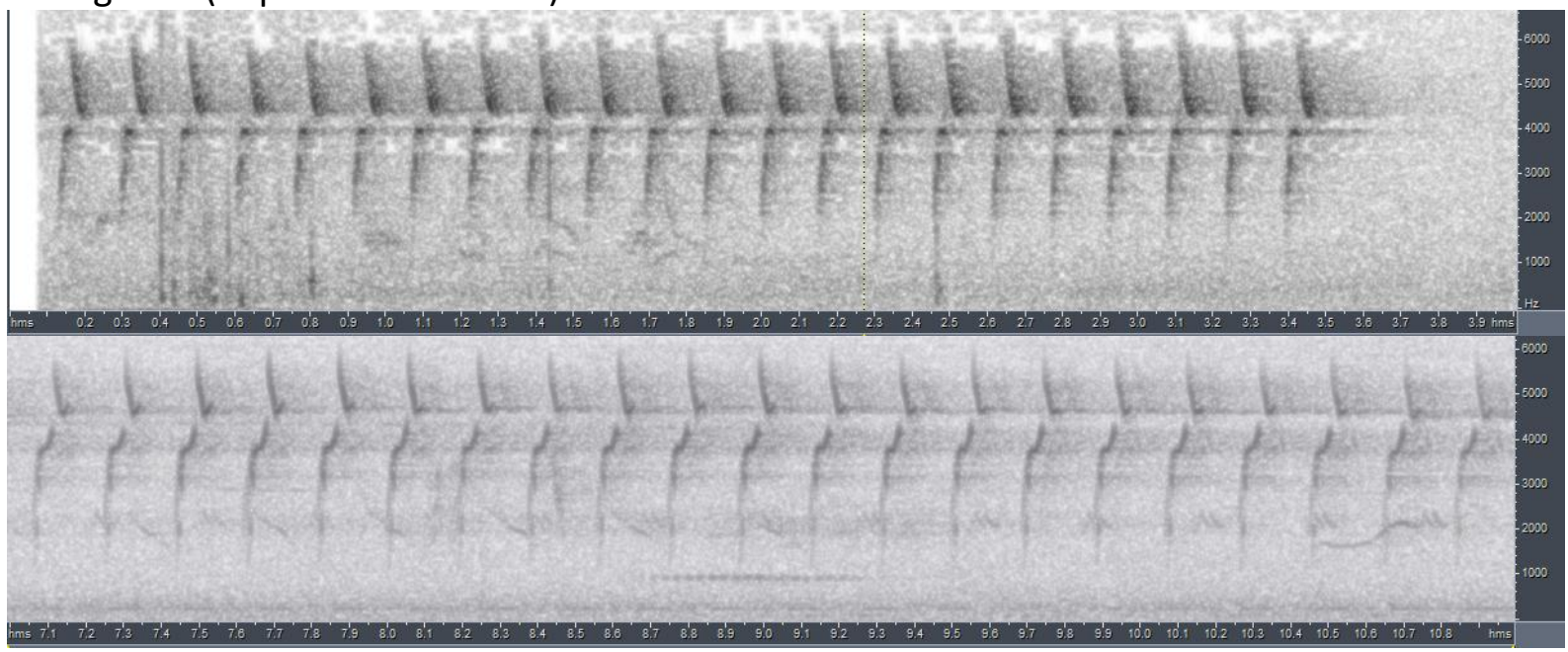



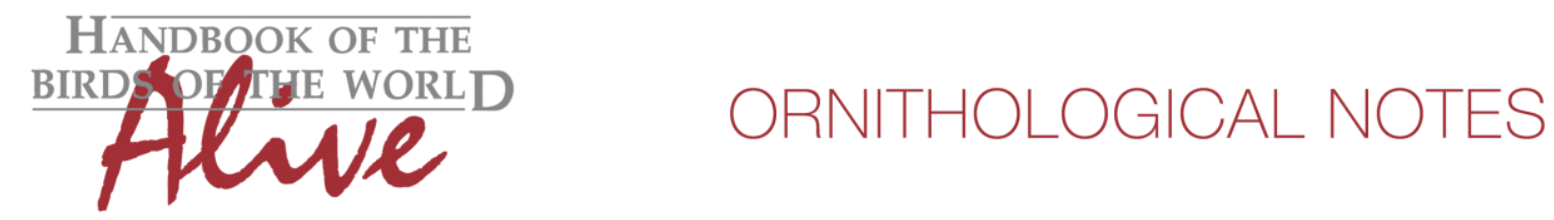

Bwamba forest

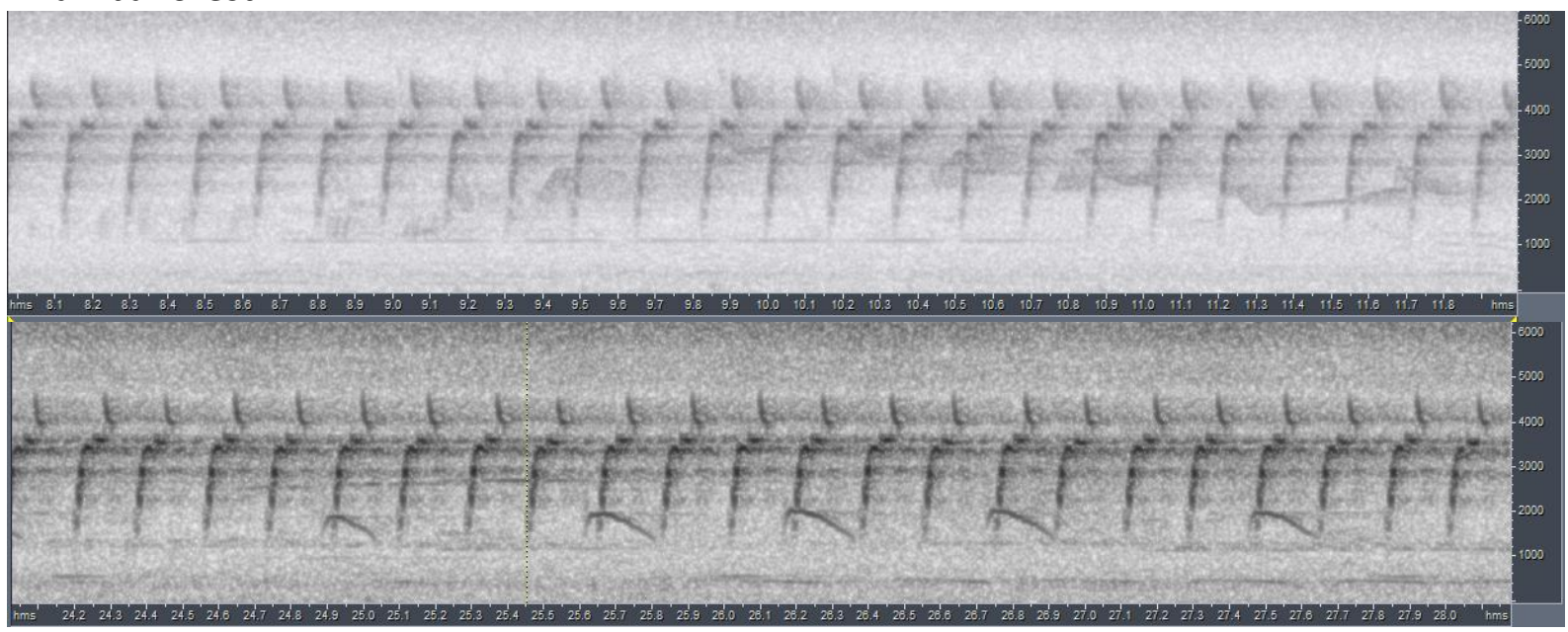

These vocalizations are slightly less complex than above examples from Cameroon /Gabon (bairdii) but clearly related. It is however not clear to which taxon these recordings belong (both bairdii and obscura occur in W Uganda, the latter occurring at higher elevations). 'Impenetrable forest' (elevation $>1190 \mathrm{~m}$ ) and 'Bwamba forest' (elevation 670-760m) are not exclusively at high elevation, and may thus be bairdii (but sonogram example 2 of obscura apparently also is of rather low elevation).

A video (http://ibc.lynxeds.com/video/banded-prinia-prinia-bairdii/bird-sunlight-later-preening) from impenetrable forest is indicated to be ssp obscura, but the bird clearly has some barring on throat, so based on plumage (and voice) it might rather be bairdii, while a picture from the same area (http://www.hbw.com/ibc/photo/banded-prinia-prinia-bairdii/black-faced-prinia) taken at $2251 \mathrm{~m}$ elevation clearly is obscura based on the solid black throat.

IF the above voice examples from Uganda are indeed of bairdii, then vocal difference between obscura/melanops and bairdii seems to be rather significant. Vocal difference between bairdii and obscura/melanops can be expressed based on the repeated composed note $v s$. a repeated single note (score 2-3) and difference in note length (many short vs one long; score 2), which would lead to a total vocal score of 4-5.

There is clearly need for a more thorough vocal study, which should in particular focus on the situation in Uganda.

This note was finalized on 11th February 2016, using sound recordings available on-line at that moment. We would like to thank in particular the sound recordists who placed their recordings for this species on XC and ML: Jacob Cooper, Peter Kaestner, Mike Nelson, Bram Piot, Mark Robbins and Keith Stuart.

\section{References}

Tobias, J.A., Seddon, N., Spottiswoode, C.N., Pilgrim, J.D., Fishpool, L.D.C. \& Collar, N.J. (2010). Quantitative criteria for species delimitation. Ibis 152(4): 724-746. 


\section{Recommended citation}

Boesman, P. (2016). Notes on the vocalizations of Banded Prinia (Prinia bairdii). HBW Alive Ornithological Note 230. In: Handbook of the Birds of the World Alive. Lynx Edicions, Barcelona. (retrieved from http://www.hbw.com/node/932191 on 28 September 2016). 